\title{
Proceeding
}

9th INSHS International Christmas Sport Scientific Conference, 4-6 December 2014. International Network of Sport and Health

Science. Szombathely, Hungary

\section{Orienteering: spatial navigation strategies and cognitive processes}

\author{
PIO ALFREDO DI TORE $\triangle$, FELICE CORONA, MAURIZIO SIBILIO \\ Department of Human, Philosophical and Education Sciences (DISUFF), University of Salerno, Italy
}

\begin{abstract}
Di Tore, P.A., Corona, F., \& Sibilio, M. (2015). Orienteering: spatial navigation strategies and cognitive processes. J. Hum. Sport Exerc., 9(Proc1), pp.S507-S514. This work argues how the cognitive processes involved in the orienteering peculiar activities (map reading, path finding, and spatial thinking) are also involved in the management of intersubjective relationship. In essence, the skills involved in reading maps and in developing strategies for spatial navigation are skills that allow us to see the world from different points of view, abandoning the egocentric perspective. To get out from egocentrism means being able to see the reality from several points of view, however other than our own. In this perspective, the work develops describing orienteering as a sport, and facing a review of scientific literature on the cognitive processes involved in spatial navigation and management of spatial reference systems, in light of the contribution made to this specific field studies from neuroscience. The work thus illustrates the spatial theory of empathy and concludes with a proposal for the spread of orienteering as an effective teaching practice in inclusion-oriented education contexts and as a powerful learning resource for Special Educational Needs. Key words: ORIENTEERING, SPATIAL REFERENCE FRAMES, SPATIAL NAVIGATION, SPECIAL EDUCATIONAL NEEDS.
\end{abstract}

\footnotetext{
Corresponding author. University of Salerno, Via Casa Leone 7, Salerno, Italy

E-mail: alfredo.ditore@gmail.com

9th INSHS International Christmas Sport Scientific Conference, 4-6 December 2014. International Network of Sport and

Health Science. Szombathely, Hungary.

JOURNAL OF HUMAN SPORT \& EXERCISE ISSN 1988-5202

(c) Faculty of Education. University of Alicante

doi:10.14198/jhse.2015.10.Proc1.45
} 


\section{INTRODUCTION}

In the scientific literature, several times orienteering was listed as a learning resource with an undisputable potential for integration and inclusion.

According to International Orienteering federation, "orienteering is a sport where competitors navigate independently through unknown terrain. The winner is the competitor that visits a number of control points marked in the forest in the shortest possible time using only map and compass. The course, defined by the location of the controls, is not revealed to competitors until they start" (International Orienteering Federation, 2011).

The reasons for this "inclusive potential" have been gradually identified in non-peculiar orienteering features (outdoor activities, competition), in general or in relation to particular types of disabilities (first of all, see the orienteering as a tool for the inclusion of the blind child).

This work argues how the cognitive processes involved in the orienteering peculiar activities (map reading, path finding, and spatial thinking) are also involved in the management of intersubjective relationship.

In particular, the work adopts the hypothesis of Alain Berthoz on the spatial theory of empathy, which closely links the ability to manage spatial reference systems with the ability to establish relationships with others.

By accepting this hypothesis, the practice of orienteering result, in terms of education, particularly functional in training programs geared to inclusion of pupils with difficulties, not only by virtue of generic, albeit scientifically documented, potential benefits of outdoor development for children with special needs (Farnham \& Mutrie, 1997), but because the practice of orienteering help and boost the brain mechanisms that allow us to adopt the point of view of others.

Potential benefits of outdoor development for children with special needs. Not surprisingly, Berthoz suggests how the brain areas involved in spatial navigation and in management of spatial reference systems are also involved in a wide variety of disorders and diseases, and therefore as the manipulation of spatial reference systems can be a transnosographic trait in various neurological and psychiatric disorders (autism, schizophrenia, epilepsy, spatial anxiety, Parkinson) (Berthoz, 2013).

\section{MATERIAL AND METHODS}

In this perspective, the present work develops describing orienteering as a sport, emphasizing interfaces with current Italian guidelines for the first cycle of education, and facing a review of scientific literature on the cognitive processes involved in spatial navigation and in management of spatial reference systems, in light of the contribution of neuroscience to this specific field of study (Carlomagno, Di Tore \& Sibilio, 2013). The work thus illustrates the spatial theory of empathy and concludes with a proposal for the spread of orienteering as effective teaching practice in educational contexts oriented to inclusion of pupils presenting Special Educational Needs.

The character of the work is mainly related to a deductive approach: as the processes involved in interpersonal relationships are also involved in the practice of orienteering, train and develop the peculiar abilities of orienteering contributes to the consolidation of skills necessary to intersubjective relationship, 
especially in the presence of special educational needs. If, for example, autism is, with Baron-Cohen and Wheelwright (Baron-Cohen \& Wheelwright, 2004), an "empathy disorder," and empathic abilities are related to the management of spatial reference systems, then the practice of activities that develop the skills of management of spatial reference systems can have positive effects on the treatment of autism spectrum disorders.

If it is true that some of the theories mentioned in this paper are still awaiting definitive experimental confirmation, it is also true that an "advantage of deduction is its ability to permit speculations on the basis of unproven premises. We do not need to await confirmation of uncertain information. We can assume that it is accurate, and then proceed to see what follows. Researchers who take this tack, of course, need to be frank about the tentative status of their premises. If later research confirms them, their deductions will stand. If premises are eventually shown to be inaccurate, then new deductions will need to be carried out" (Thomas, Nelson, Silverman \& Silverman, 2010).

\section{RESULTS}

\section{Orienteering and education}

Golden, Levy e Vohra provide a detailed definition that specifies the procedural activities to which is called the performer who takes part in an orienteering event:

"Orienteering is an outdoor sport that is usually played in heavily forested areas. Located in the forest are a number of "control points" each with an associated score. Competitors armed with compass and map are required to visit a subset of the control points from the start point (node 1) so as to maximize their total score and return to the end point (node n) within a prescribed amount of time" (Golden, Levy \& Vohra, 1987)

Given the type activities, it is easy to deduce how the scientific approach to orienteering invests a good variety of knowledge fields (cartography, geography, medicine, sports science, education, psychology and neuroscience) that often are not considered contiguous.

From the educational point of view, this sport already has an established tradition of exchange and interaction with school activities:

"The educational value provided by orienteering's blend of navigational and physical skills has given it a permanent place in the primary and secondary school curriculum in the United Kingdom" (McNeill, CoryWright \& Renfrew, 1998).

In Italy orienteering is officially recognized by the Ministry of Education and Research with several ministerial circulars, including that of 12 November 1998 that contains the terms of cooperation between the Inspectorate for Physical Education and Sports and Italian Federation Orienteering Sports (FISO).

This is not surprising, when you consider that the Italian Guidelines for the kindergarten and the first cycle of education, among learning objectives that pupils should achieve at the end of the third class of secondary school degree, cite the ability to identify to know how to orient into the natural environment through the reading and decoding of maps. 


\section{Spatial reference frames}

To know how to steer into the environment, according to an expression adopted by the Italian guidelines, involves the ability to develop a functional representation of the environment in question. While navigating in space, in fact, proprioceptive, visual, vestibular and motor information are combined to extract spatial invariant and to draw a representation of the environment. A key concept in the field of spatial processing regards the definition of the reference systems used by the central nervous system to interpret the sensory information and to locate objects in space. The expression "reference systems" refers here to the systems of coordinates by which the central nervous system encodes the relative positions of objects in space, including that of the body itself (Gaunet \& Berthoz, 2000).

Simply stated, a reference system is a way of representing the positions of the subjects / objects in space.

The spatial position of an object can be represented in the brain with respect to different classes of reference points, which may be related or independent of the position of the subject.

Spatial representations, allocentric and egocentric, significantly differ. Spatial information provided by an allocentric representation refer to a space outside the perceiver; the information provided by an egocentric representation refer to a person who perceives with a defined orientation axis. In particular, the representation allocentric encodes the positions of the points in space in a similar manner to a system of Cartesian or polar coordinates. The egocentric representation uses a special polar coordinate system whose origin is the ego (the perceiving subject) and the reference axis is the axis of orientation of the subject, encoding the position of a point in terms of distance and angle to the subject (Di Tore, 2014).

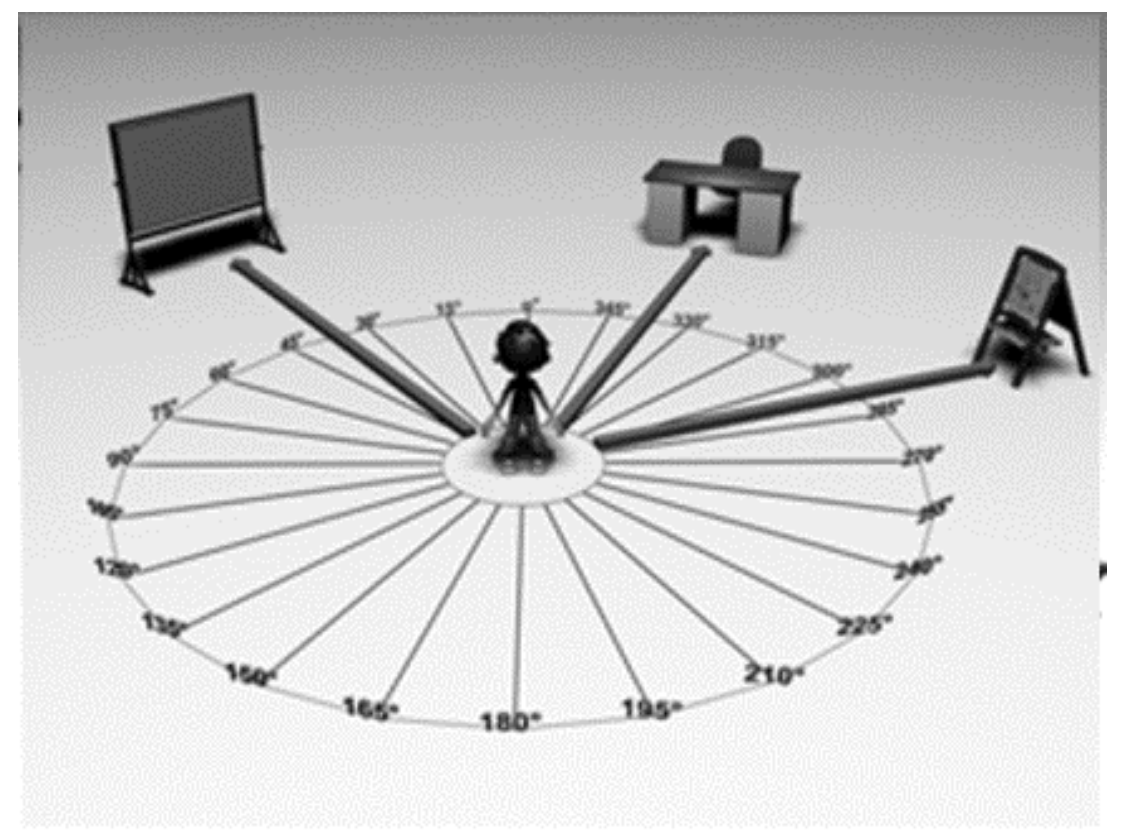

Figure 1. Egocentric Reference System

It is possible therefore to affirm that there are two types of transformations of space imagery: the allocentric spatial transformations, that involve a system of representation from object to object and encode information about the location of an object or its parts in relation to other objects, and egocentric spatial transformations, involving a subject-object representation system. 
An early formulation of a theory of the stages of development of spatial thinking is illustrated by Piaget in "la représentation de l'espace chez l'enfant"

Piaget's ideas on mental development have focused on egocentrism in early childhood, on the basis of experimental studies, such as the three mountains problem (Piaget \& Inhelder, 1948).

In this test, a child must indicate the point of view of an observer who is in a different location.

According to Piaget's results, "only around the age of eight "intellectual space will be built, able to definitely prevail on perceptible space and to allow manipulation of points of view that combines a series of mechanisms of representation" (Piaget \& Inhelder, 1948).

\section{From perspective taking to spatial theory of empathy}

Alain Berthoz proposes a spatial theory of empathy which locates in perspective taking the fundamental difference between sympathy and empathy meant as modes of intersubjective relationship. Sympathy for Berthoz, is to attribute "à nous-mêmes ce que nous observons dans l'autre. Un tel procédé 'attribution peut impliquer que nous localisons ou simulons l'autre dans nous-mêmes et nous identifions avec lui. Mais dans ce processus de sympathie, nous restons à notre place et voyons l'autre de notre propre point de vue" (Berthoz, 2013).

In the relationship based on sympathy, then, we remain in our place, we continue to see things from our point of view, while undergoing a process of emotional contagion. On the contrary, a fundamental characteristic of empathy, in this sense, is to take the point of view of others, simultaneously inhibiting the emotional contagion. The theory of Berthoz (Berthoz, 2004), gained in the studies about Physiologie du changement de point de vue, is a continuation of the phenomenological tradition: "in relation to a modern conception of the philosophical tradition of phenomenology and a primary role of cognitive embodiment" Berthoz showed "that there is a basic difference between sympathy and empathy. While sympathy is akin to an emotional contagion and does not require the subject to adopt the point of view of others, empathy requires a dynamic and complex manipulation of spatial reference systems" (Berthoz \& Thirioux, 2010).

Berthoz hypothesis is that the empathic processes require the contribution (albeit not exclusively) of different brain mechanisms involved in spatial perception, in the mental manipulation of the reference systems and in perspective taking. Berthoz cautions on the use of the term manipulation: "En effet, nous changeons en permanence de référentiels. J'utilise pour désigner cette action le terme de «manipulation de référentiels spatiaux », bien qu'il s'agisse d'une opération mentale et non manuelle. Selon moi, une telle richesse du répertoire de référentiels potentiels permet la vicariance fonctionnelle " (Berthoz, 2013).

In the case of empathy, the brain performs a mental déplacement, a simulated rotation of the body in space, a mental manipulation on ourselves and on the objects of the environment through a process that Berthoz defines "mise à jour spatiale". By adopting this approach, empathy is a mode that allows us to relate to each other without attributing to ourselves what the other experiences, rather than entering into the body of others to assume the point of view, or to see the world with the eyes of others.

\section{Spatial navigation, map reading and cognitive processes}

The path selection is undoubtedly a key factor for success in orienteering: "There is no doubt that good route selection and proper execution of the five techniques along your route are keys to success in orienteering" (Ferguson \& Turbyfill, 2013). 
Orienteering involves not only the cognitive processes associated with spatial navigation, but also the "combined task (as well as subtasks) of map reading and navigation" (Lobben, 2004).

These tasks are not separate moments but are closely linked together.

Alain Berthoz and his research team hypothesized that "a previously performer 'oculomotor navigation' on a map could be used by the brain to perform a locomotor memory task" (Demichelis, Olivier \& Berthoz, 2013).

The contribution of neuroscience in the investigation of this specific subject of studies (spatial navigation and map-reading) is proving to be very significant in bridging a gap, probably due to the hybrid nature of the research field (Di Tore, D'Elia, Aiello, Carlomagno \& Sibilio, 2012).

Just a few years ago, Amy Lobben emphasized how "research into cognitive processes in map reading has been conducted primarily in the fields of psychology and cartography. [...] Cognitive studies and spatial ability measures have been conducted for more than 100 years by psychologists and for more than 30 years by cartographers. However, while some studies provide insight into the cognitive processes and strategies associated with specific map-reading tasks, many of these tasks, strategies, and processes have yet to be identified and, possibly more importantly, understood" (Lobben, 2004).

\section{Four strategies for Spatial Navigation}

Allocentric and egocentric representations, mentioned earlier, are the basis of the respective strategies of spatial navigation:

"In animals as well as in humans, two main strategies have been described for goal-oriented navigation: the allocentric strategy based on a world centered representation and the egocentric strategy centered on the navigator (Maguire et al., 1998; Berthoz, 2001; Bohbot et al., 2002; Burgess et al., 2002). Allocentric strategy (also called map-based strategy) is now well defined and requires encoding interrelationships among environmental cues' position, movements, and the location of the goal (Tolman, 1948; O'Keefe \& Nadel, 1978; Burgess et al., 2002).

Egocentric strategy, by contrast is a less well-defined concept" (Iglói, Zaoui, Berthoz \& Rondi-Reig, 2009). On the basis of an experimental study, Berthoz stated that "sequential egocentric strategy can be spontaneously acquired at the onset of the training as well as allocentric strategy. Allocentric and sequential egocentric strategies could be used together within a trial, and bidirectional shifts (between trials) were spontaneously performed during the training period by $30 \%$ of the participants. Regardless of the strategy used spontaneously during the training, all participants could execute immediate shifts to the opposite none previously used strategy when this strategy was imposed. Altogether, our findings suggest that subjects acquire different types of spatial knowledge in parallel, namely knowledge permitting allocentric navigation as well as knowledge permitting sequential egocentric navigation" (Iglói et al., 2009).

Berthoz, in La vicariance (Berthoz, 2013), offers a more detailed classification of cognitive strategies for spatial navigation, identifying four main types: self-centered strategy, allocentrica strategy, heterocentric strategy and the strategy that he defines as maquette3d.

"The first of these cognitive strategies can be called "egocentric strategy". When we visit a city on foot or by car, it is to remember our movements, detours we had to do, and to associate visual cues that we have 
seen or events that we have experienced. We called it "kinesthetic memory route." It is not limited to a simple combination of movements and sensory data" (Berthoz, 2013).

"The second strategy has been identified by psychologists as an allocentric overview strategy. It evokes a mental map of the environment, on which we can follow a route as well as on a real map. the second strategy is called allocentric because it does not involve your body. Environmental elements are in fact linked together without any reference to the body of the person who examines the space. This strategy of displaying a map is important when we try to remember long distances or plan a trip among other possible. It is probably at the root of our ability to do geometry. It appears late in children, together develop structures such as the hippocampus and the prefrontal cortex.

The third strategy is said hetérocentric. If someone asks us how to go to the post office from his hotel, and we describe the way he will make from his "point of view", we must take that person as a reference. This shift also occurs when an altercation occurs, and we try to understand the views of the protagonists.

A fourth strategy was described when, for example, we try to remember the location of the office of one of our colleagues in a building. In this case, the brain develops a representation of the building through a sort of transparent model of the building. I call this strategy "3D model" because it is to build a mental model of a three-dimensional structure. Few studies have been devoted to this question. Yet it is useful when we travel on the subway, in hospital, etc" (Berthoz, 2013).

\section{CONCLUSIONS}

In the life of every day, we change constantly reference systems, and we even use several simultaneously. Berthoz proposed the idea that the choice of an oblique perspective for the presentation of GPS is due to the fact that if a path is presented from an oblique perspective, the brain can encode the way in both egoallocentred reference systems. This allows him, upon recall, to the information stored in one of two standards, depending on the task and context

Berthoz advanced the hypothesis that Manipulation of spatial reference systems constitute a "transnosographic trait" in various neurological and psychiatric disorders. Each of these diseases (autism, schizophrenia, epilepsy, spatial anxiety, Parkinson) reaches some of the structures involved in the manipulation of referential of different spaces.

This paper presents a theoretical-argumentative study about how the cognitive processes involved in the orienteering peculiar activities (reading maps, identifying routes, spatial thinking) are processes involved in the management of intersubjective relationship. In essence, the skills involved in reading maps and in developing strategies for spatial navigation are skills that allow us to see the world from different points of view, abandoning the egocentric perspective, and are therefore to be involved in all inclusion-oriented educational programs.

"To get out from egocentrism means being able to see the reality from several points of view, however other than our own" (Trisciuzzi \& Zappaterra, 2011). 


\section{REFERENCES}

1. Baron-Cohen, S., \& Wheelwright, S. (2004). The empathy quotient: an investigation of adults with Asperger syndrome or high functioning autism, and normal sex differences. Journal of autism and developmental disorders, 34(2), pp.163-175.

2. Berthoz, A. (2004). Physiologie du changement de point de vue. In A. Berthoz \& G. Jorland (Eds.), L'empathie (pp. 251-275). Paris: Odile Jacob.

3. Berthoz, A. (2013). La Vicariance: Le cerveau créateur de mondes. Paris: Odile Jacob.

4. Berthoz, A., \& Thirioux, B. (2010). A Spatial and Perspective Change Theory of the Difference Between Sympathy and Empathy. Paragrana, 19(1), pp.32-61.

5. Carlomagno, N., Di Tore, P.A., \& Sibilio, M. (2013). Motor activities teaching and complexity: a reversal of the classical description of the mechanisms of perception and action. Journal of eLearning and Knowledge Society, 9(3), pp.55-66.

6. Demichelis, A., Olivier, G., \& Berthoz, A. (2013). Motor transfer from map ocular exploration to locomotion during spatial navigation from memory. Experimental brain research, 224(4), pp.605611.

7. Di Tore, P.A. (2014). Perception of Space, Empathy and Cognitive Processes: Design Of A Video Game For The Measurement Of Perspective Taking Skills. International Journal of Emerging Technologies in Learning (iJET), 9(7), pp.23-29. http://dx.doi.org/10.3991/ijet.v9i7.3718

8. Di Tore, S., D'Elia, F., Aiello, P., Carlomagno, N., \& Sibilio, M. (2012). Didactics, movement and technology: new frontiers of the human-machine interaction. Journal of Human Sport and Exercise, 7(1), pp.178-184. http://dx.doi.org/10.4100/jhse.2012.7.proc1.20

9. Farnham, M., \& Mutrie, N. (1997). Research Section: The Potential Benefits of Outdoor Development for Children with Special Needs. British Journal of Special Education, 24(1), pp.3138.

10. International Orienteering Federation (2011). Competition rules for International Orienteering Federation (IOF) foot orienteering events. Retrieved from http://orienteering.org/wpcontent/uploads/2010/12/IOF-Foot-Orienteering-Rules-2011.pdf

11. Ferguson, C., \& Turbyfill, R. (2013). Discovering Orienteering: Skills, Techniques, and Activities. USA: Human Kinetics.

12. Gaunet, F., \& Berthoz, A. (2000). Mental rotation for spatial environment recognition. Cognitive brain research, 9(1), pp.91-102.

13. Golden, B.L., Levy, L., \& Vohra, R. (1987). The orienteering problem. Naval research logistics, 34(3), pp.307-318.

14. Iglói, K., Zaoui, M., Berthoz, A., \& Rondi-Reig, L. (2009). Sequential egocentric strategy is acquired as early as allocentric strategy: Parallel acquisition of these two navigation strategies. Hippocampus, 19(12), pp.1199-1211.

15. Lobben, A. K. (2004). Tasks, Strategies, and Cognitive Processes Associated With Navigational Map Reading: A Review Perspective. The Professional Geographer, 56(2), pp.270-281.

16. McNeill, C., Cory-Wright, J., \& Renfrew, T. (1998). Teaching orienteering. Champaign, IL: Human Kinetics.

17. Piaget, J., \& Inhelder, B. (1948). La représentation de l'espace chez l'enfant. Paris: Presses Universitaires De France.

18. Thomas, J.R., Nelson, J.K., Silverman, S., \& Silverman, S.J. (2010). Research methods in physical activity. USA: Human Kinetics Publishers.

19. Trisciuzzi, L., \& Zappaterra, T. (2011). Dislessia, disgrafia e didattica inclusiva. Annali della Pubblica Istruzione, 2, pp.51-76. 